\title{
Rescritas cénicas da ópera King Priam, de Michael Tippett, nos séculos XX e XXI
}

\author{
ANA RITA FIGUEIRA
}

Cette recherche se tâche d'essayer les notions « archive prétexte » et « œuvre en movement » (Féral) dans une étude de cas sur l'opéra King Priam du compositeur, librettiste et pacifiste britannique Michael Kemp Tippett (1908-1998). Inspiré par L'lliade d'Homère cet opéra, à thématique guerrière, traite des sujets de toutes les époques, tels que le conflit et le choix, continuant à être joué depuis plus d'une cinquantaine d'années. Pour aboutir à cette finalité-là, un « moment choisi » (Féral) est analysé en trois réécritures scéniques (1962, 1985 et 2014) de cette œuvre, résolument théâtrale dès sa conception. La perspective comparatiste amène, d'un côté, à initier le retracement de I'histoire génétique de King Priam et, de l'autre, soulever des questions concernant l'articulation entre les notions ci-dites, l'espace et le temps. Cette méthode permettra d'identifier des solutions scéniques qui, tout en étant distinctives de leur époque, gardent, pourtant, des traits des réécritures précédentes, contribuant ainsi à éclairer le sens des notions étudiées. Cette étude termine en soulevant la question suivante: « Dans quels termes peut-on comprendre les notions "archive prétexte" et "œuvre en movement" dans le cadre d'un opéra itinérant tel que la dernière scénographie de King Priam? »

KING PRIAM / ARCHIVE PRÉTEXTE / EEUVRE EN MOUVEMENT / MOMENT CHOISI / SCÉNOGRAPHIE

1.

Este estudo incide sobre as noções de «arquivo pretexto» e «obra em movimento» (Féral, [s. d.]: 5), em articulação com o espaço cénico de três cenografias da ópera King Priam, obra inspirada na Ilíada de Homero, que distam cerca de três décadas umas das outras (1962, 1985, 2014 $)$. Precisamente, esta pesquisa analisa os espaços cénicos (figs. 1-3), em geral e, em particular, a cena do resgate do corpo de Heitor (ver figs. 6-8), que constitui um momento seleccionado («moment choisi», Féral, [s. d.]: 6). Assim, presta-se atenção aos modos de representação do tempo e do

1 Outras rescritas cenográficas ocorreram em 1991 e, em versão concerto, em 2003. 
espaço, de maneira a determinar alterações em cada universo cénico referido, notando a maneira como estes incorporam a atmosfera do seu tempo, particularmente no que diz respeito à representação da compaixão.

Aquelas opções pretendem responder à seguinte pergunta: o que dizem as rescritas cénicas em estudo acerca das noções de «arquivo pretexto» e «obra em movimento»; em particular, o que dizem os traços distintivos da sua época de produção acerca daquelas noções?

A ópera King Priam está solidamente estudada (Kemp, 1965; Heberle 2006; Clarke, 2001), todavia a produção científica sobre as suas concepções artísticas é rara ou inexistente, como é o caso de estudos orientados sob o ponto de vista da genética teatral. Diferentemente destes, esta pesquisa, em primeiro lugar, oferece um estudo de caso em que se procura demonstrar o modo como estas cenografias, como parte do processo criativo (Féral, 2007), vivificam e manipulam a atmosfera clássica (Grécia Antiga), favorecendo a atribuição do estatuto de arquivo pretexto à primeira rescrita (1962), enfatizando, assim, a sua vitalidade e a sua longevidade. Em segundo lugar, objectiva-se mostrar por que King Priam se pode designar como uma obra em movimento, nomeadamente na dimensão de organismo cenográfico, isto é, como uma obra que vive há mais de cinquenta anos.

\section{2.}

Esta segunda ópera do compositor britânico Michael Kemp Tippett (1905-1998), também autor do libreto, foi representada em antestreia a 29 de Maio de 1962, por ocasião da reconstrução da Catedral de Coventry. A carga simbólica desta cidade, destruída durante os bombardeamentos da Segunda Grande Guerra, contribuiu para acentuar a mensagem pacifista desta ópera, que equaciona as consequências universais do arbítrio individual. Influenciado pela psicanálise de Jung, o compositor perscruta os abismos do psiquismo humano, onde se incluem as múltiplas divisões da personalidade, criando, por exemplo, papéis duplos para as personagens. Desta maneira, as mulheres estão associadas às deusas: Hécuba (Atena), Hera (Andrómaca) e Afrodite (Helena), o que reforça a densa trama de relações e de personalidades entrecruzadas (Clarke, 2001, 13-32). 


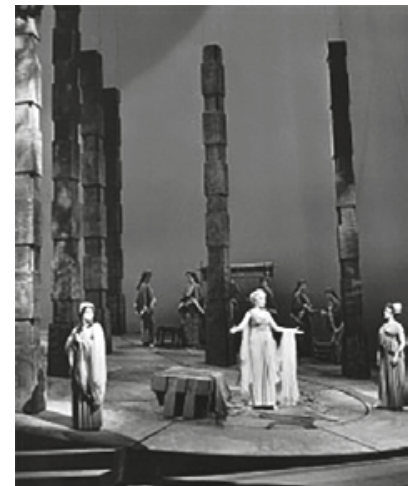

FIG. 1

KING PRIAM, DE MICHAEL TIPPETT, ENC. SAM WANAMAKER, ROYAL OPERA HOUSE, 1962, [F] HOUSTON ROGERS

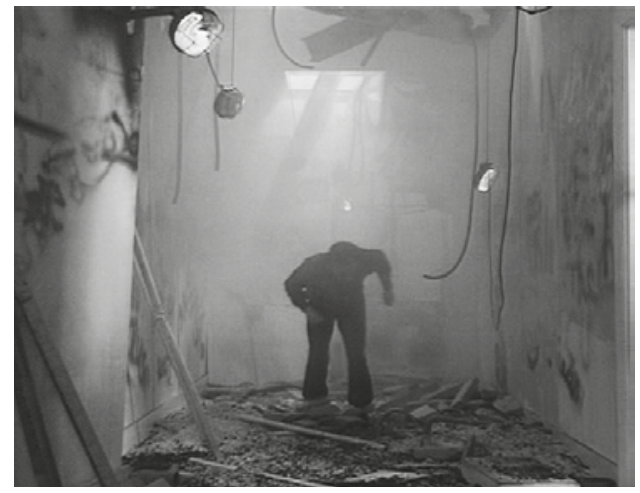

FIG. 2

KING PRIAM, DE MICHAEL TIPPETT, ENC. ROBIN LOUGH, 1985, [F] RM ARTS

Estruturalmente King Priam tem três actos, cujas cenas, breves, se articulam em mosaico. Os conflitos ${ }^{2}$ são apresentados objectivamente pelas personagens, sem que nenhum ponto de vista exterior àquelas seja sugerido. Os diálogos e, sobretudo, os monólogos, longos e frequentes, assemelham esta ópera a um laboratório de pensamento mediado, em termos cénicos, por uma plataforma inclinada na direcção da audiência, distanciando-se desta, por um lado, e por outro lado interpelando-a. ${ }^{3}$

King Priam é uma ópera particularmente teatral (cf. Wanamaker, 1992; P. A. 1962; Porter, [1962?]), com muitas árias quase declamadas, de tal modo que a música, por vezes, passa despercebida (cf. Tippett, 1962: 13). Trata a temática da Guerra de Tróia do ponto de vista do rei Príamo, em vez de acompanhar o tema da Ilíada, isto é, a cólera de Aquiles. O primeiro acto mostra o rei Príamo absorto num dilema moral devido à antevisão do Ancião adivinho, de acordo com a qual Páris, o príncipe recém-nascido, causará a sua morte. Cedendo à insistência da mulher, a rainha Hécuba, Príamo ordena a morte de Páris para preservar Tróia. Anos depois, o rei reencontra o seu filho, cuja vida fora preservada pelo guarda a quem Príamo ordenara a sua morte. O rei regressa a Tróia com Páris, na esperança de se redimir do seu arbítrio anterior. Mais tarde, Páris adulto, na sequência de um desentendimento

2 Uma das seis categorias trágicas achadas por Serra (2006: 196-437). As outras são o destino, a liberdade, a culpa, o conhecimento e a ignorância.

3 Origina-se um efeito de estranhamento e um efeito de absorção (Marin, 1988), que procuram sugerir técnicas brechtianas, também observáveis nas cenas independentes e objectivas (apud Pollard e Clarke, 1998: 66-185). Para a problemática da percepção da audiência, ver entre outros McConachie (2007). 
com Heitor, seu irmão mais velho, parte para Esparta, onde visita a corte do rei Menelau e se apaixona pela sua mulher, a rainha Helena, regressando com esta a Tróia e desencadeando a guerra. Heitor mata Pátroclo, devoto companheiro de Aquiles, e este mata Heitor, profanando-lhe o cadáver. $O$ velho Príamo suplica a Aquiles que lhe devolva o corpo morto de seu filho, ao que o herói, por fim, consente. Tróia é destruída; Páris mata Aquiles; o filho de Aquiles mata o filho de Heitor e o rei Príamo. As mulheres, isoladas, serão escravizadas.

Esta ópera é, todavia, muito mais do que um dominó de mortes. Estas acontecem na consequência de necessidades e de constrangimentos exteriores às personagens, tais como a dupla condição que as subordina, criando uma tensão entre o privado e o público, como é o caso de Príamo, cuja condição de pai colide com o seu papel de rei. As mortes e os arbítrios respondem genuinamente à vocação ou, inversamente, tentam silenciá-la, na esperança de tomar a decisão acertada. Consequentemente, a existência das personagens desenha um conjunto de fragmentos aparentemente desligados, onde o destino se intromete, como fio condutor invisível que o articula, descrevendo uma realidade complexa e circular de arbítrios e consequências destes. Neste contexto, a compaixão aparece como acto unicamente humano e resolutamente trágico (apud Figueira, 2013: 63-79), no seio das perdas mais violentas e dos actos mais cruéis, subordinando todos ao páthos, como sugerem as lanternas triangulares erguidas ao alto, reproduzindo a tenda de Aquiles, lugar de violência e de compaixão (cf. infra). Tal acto coral constitui uma solução cénica que sobressai como «momento cristalizado», indicador da pergunta minimalista: porquê?

\section{3.}

Grésillon (2005: 5) formulou e sistematizou uma série de questões de fronteira acerca da investigação em genética teatral, entre as quais a referência ao tesouro de leituras disponível na memória dos leitores. Esta questão autoriza compreender os textos como organismos vivos, uma vez que a sua confluência com o leitor os fertiliza, o que engendra um encadeamento de arquivos pretexto, enfatizando o estatuto de «obra em movimento» do arquétipo. As rescritas cénicas de King Priam mostram uma dinâmica semelhante, porque o libreto é constituído por múltiplos fragmentos, fruto do cruzamento de fontes gregas, directas ou indirectas, 


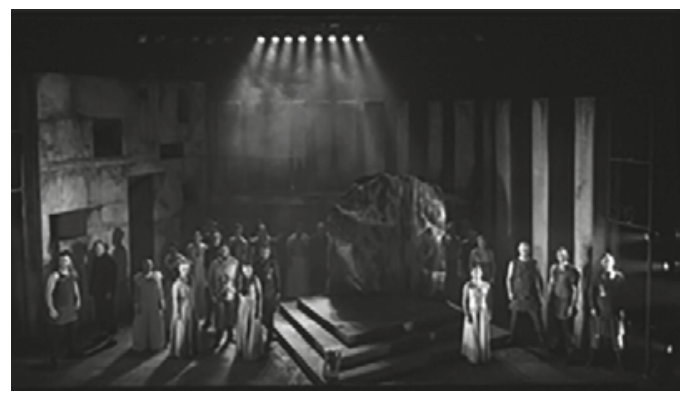

FIG. 3

KING PRIAM, DE MICHAEL TIPPETT, ENC. JAMES CONWAY, ENGLISH TOURING OPERA, 2014, [F] RICHARD HUBERT SMITH

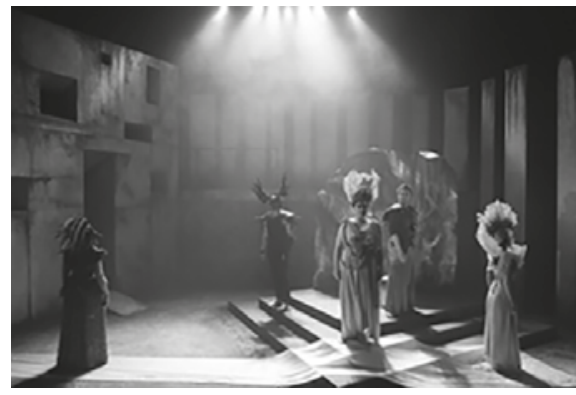

FIG. 4

KING PRIAM, DE MICHAEL TIPPETT, ENC. JAMES CONWAY, ENGLISH TOURING OPERA, 2014 [F] RICHARD HUBERT SMITH

com múltiplas alusões culturais (apud Robinson, 2002), estimulando a reinvenção, onde se inclui um jogo interminável de interferências culturais da época que as recria.

Efectivamente, a construção que dá a ver o texto utiliza ferramentas hermenêuticas, ou seja, soluções entre o escrito e o não escrito, entre aquilo que é mostrado e aquilo que não se vê, de maneira que as possibilidades de rescrita se multiplicam proporcionalmente ao ritmo das perspectivas intervenientes, como propõe Grésillon:

S'il y avait recouvrement total, il ne pourrait y avoir qu'une seule représentation possible, qui serait alors entièrement inscrite dans le texte-comme si le texte et le cahier de régie contenaient les mêmes choses. Or, on sait depuis toujours qu'à la relative pérennité et unicité du texte s'oppose le caractère éphémère et multiple des mises en scènes. De cette illusion de recouvrement total relève [...] la conception du texte comme cause première et dernière: comme si la représentation n'était que la conséquence logique du texte, son achèvement, sa consécration; comme si la mise en scène n'était que l'explication visible [...] du texte. (1996: 2)

Igualmente, a cenografia também mostra uma perspectiva que se ergue da intimidade com o texto e com a música. Para identificar a gestação do gesto criativo até ao espectáculo, é necessário examinar sistematicamente os documentos que registam as etapas da criação (esboços e apontamentos de actores e de encenadores, por exemplo), de modo a descobrir «hesitações, rasuras, descobertas e escolhas diversas que acompanham o trabalho» (apud Féral, [s. d.]: 2). Por outras palavras, aqueles documentos denunciam a fragilidade das ideias inaugurais, 
contudo também descortinam o seu potencial para chegar aonde é possível. Este método viabiliza mapear a criação, que se distingue como organismo vivo, continuando com a experiência gerada entre o gesto em cena (durante o espectáculo) e o olhar da audiência. Com este encontro, o organismo sofre alterações e apropriações condutoras a fases de maturação da obra.

O estudo comparado de momentos seleccionados, registados, por exemplo, em fotografias de cena realizadas durante o espectáculo ou anteriores a este, para efeitos de promoção, possibilitou a identificação de vestígios do processo de compreensão do conflito a partir da sua representação criativa, em cada época analisada. Observou-se que tais traços se manifestam na redução e na decadência do espaço, na aceleração do ritmo e na mistura de fragmentos, distinção que se reflecte particularmente na concepção do solo (1962, ver fig. 1), na estrutura em ruínas (1985, ver fig. 2) e na mistura de materiais e de estilos no guarda-roupa (2014, ver fig. 3). Registaram-se ainda traços hereditários entre os espaços imaginários, como o desnivelamento e a depuração do espaço cénico, as formas angulares e as telas brancas, manchadas de encarnado-vivo. O minimalismo e o multifuncionalismo crescentes do espaço cénico denunciam a sua época, sugerindo a atribuição de orçamentos em diminuendo.

\section{4 .}

Para a primeira rescrita, os materiais de investigação foram esboços do espaço imaginado (ver fig. 8), de personagens, de guarda-roupa, fotografias de cena, assim como também foram considerados comentários de encenadores e crítica de imprensa. Para a rescrita de 1985, compararam-se fotografias de cena do espectáculo apresentado à Royal Opera House e fotografias do filme em DVD, onde se regista a versão para estúdio daquela representação. Para a rescrita de 2014, as fontes utilizadas foram os esboços finais do guarda-roupa, fotografias de cena, um vídeo promocional ${ }^{4}$, críticas de imprensa e uma entrevista pessoal, via correio electrónico, ao encenador James Conway.

Tais materiais descortinam a noção de «obra em movimento» como passagem do ideal ao real, isto é, ao vivente, ao concreto e ao possível. 
FIG. 5

KING PRIAM, DE MICHAEL

TIPPETT,

ENC. SAM

WANAMAKER, ROYAL OPERA HOUSE, 1992 [F] HOUSTON ROGERS

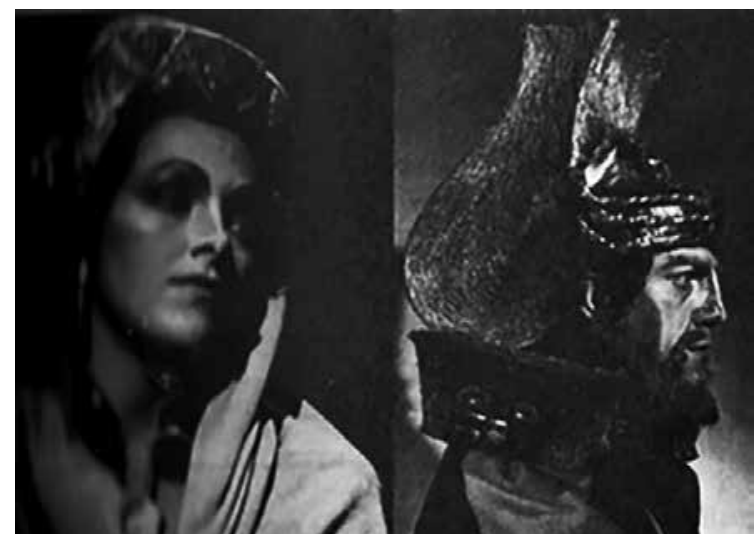

Por exemplo, em relação ao guarda-roupa, os esboços de Anna Fleischle ${ }^{5}$ para a personagem de Hermes ocultavam-lhe os olhos, mas o transporte desta concepção para uma peça real, de couro negro, tornaram a personagem semelhante a um artista de cabaré, introduzindo-se assim um matiz inesperado na representação. Todavia, esta surpresa não trai o texto, onde o sexo e a morte formam uma díade inalienável (apud John, 1985: 68).

A noção de «obra em movimento», ao referir-se à ondulação gerada pelos ajustamentos durante os ensaios (apud Féral, [s. d.]:5-6), também qualifica o espectáculo itinerante. Efectivamente, a produção de King Priam em 2014 é literalmente uma obra em movimento, pois trata-se de uma companhia itinerante (ETO), o que propicia alterações durante a performance, nomeadamente no que diz respeito à circulação e aos movimentos dos artistas, por necessidade decorrente dos diversos espaços, originando outras dramaturgias cenográficas (Howard, 2005: 46). A longevidade cénica desta ópera desde a estreia (1962) até à actualidade (2014) está na origem da compreensão de King Priam como obra em movimento, porque é possível distinguir traços hereditários da primeira rescrita nas subsequentes, da mesma maneira que se identificam traços distintivos de cada época. Desta forma, em 1962, King Priam singulariza-se devido à sua estética clássica, mostrando posturas clássicas, que sugerem um ritmo enérgico, porém suave (fig. 1). Diferentemente, a cenografia de 1985 evoca a Segunda Grande Guerra mais evidentemente, imprimindo no espaço um ritmo moderado e pesado, com posturas mais descontraídas, e, neste sentido, mais distantes da Grécia Antiga (ver figs. 2 e 7). Em 2014 (fig. 3), sobressai a mistura de estilos, o ritmo, por vezes, repentinamente frenético, como é o caso de Hermes, que se

5 Cf. http://www.annafleischle.com/king-priam?lightbox=i5aj7. 
FIG. 6

KING PRIAM, DE MICHAEL TIPPETT, ENC. SAM WANAMAKER, ROYAL OPERA HOUSE, 1992 [F] HOUSTON ROGERS [?]

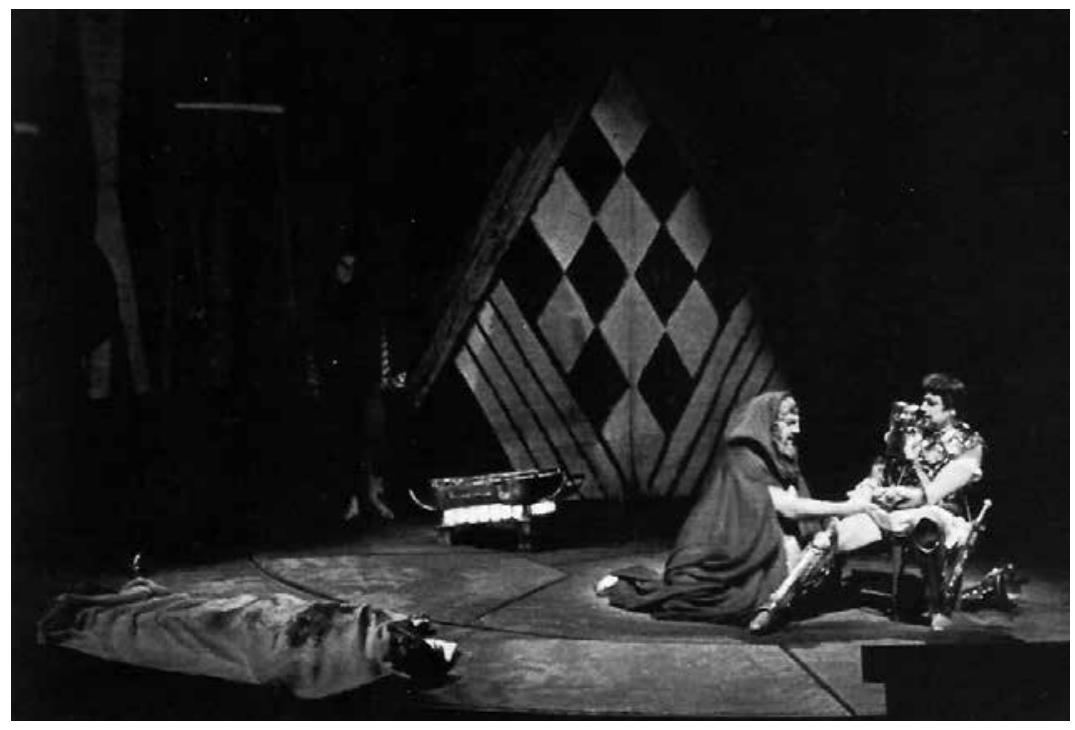

movimenta com considerável rapidez, de forma diferente da recriação de 1985 e inversamente ao que as fotografias de 1962 sugerem. O espaço parece pontualmente sobrecarregado, não se reconhecendo a Grécia de imediato, de maneira que conhecer a mitologia grega é uma vantagem. Por exemplo, os adereços sobre a cabeça de Helena assemelham-se a um cisne, evocando a paternidade da rainha de Esparta.

Por fim, o momento seleccionado, isto é, o resgate do corpo de Heitor, contribuiu para tornar a análise mais rigorosa, de maneira a esclarecer o modo como se adaptou a noção de «arquivo pretexto» relativamente à rescrita de 1962. De facto, esta dá a ver violência, sofrimento e compaixão, uma tríade universal da condição humana, mediante uma linguagem notoriamente distante das rescritas de 1985 e de 2014. Por exemplo, a cenografia de 1962 recria uma arma grega de fogo mediante um artefacto semelhante a um foguetão, evocando simultaneamente uma novidade na ciência contemporânea, solução cénica que não resultaria actualmente, pois a variável novidade teria desaparecido.

5 .

Actualmente a disponibilidade de espaço é um problema para encenar uma tragédia grega (cf. Goldhill, 2007: 7-44). Porém, King Priam não é uma tragédia grega, mas procura ser uma paráfrase contemporânea, em articulação com um matiz épico, que sugere a viagem humana desde 
a concepção até à morte. Este percurso, vinculado a uma concepção do tempo como movimento contínuo, encadeado e circular, recria a ideia musical de «ciclo», que tem uma identidade distinta, reforçando-a. O espaço é, portanto, decisivo para veicular a noção de tempo, formando uma díade indissociável, uma vez que a dimensão cronológica não pode ser desligada dos acontecimentos, nem estes são autónomos em relação àquela.

Para recriar aquela noção temporal, a produção de 1962 concebeu uma plataforma circular, onde se inclui uma rampa, que gira à volta de dois eixos distintos, accionando dois mecanismos distintos. $\mathrm{O}$ primeiro divide-a em dois planos independentes, e o segundo eleva-a até meio da plataforma principal (ver fig. 1). Esta inclui uma entrada na parte de trás e outra por baixo do solo, o que possibilita uma transição tranquila entre espaços, facilitando ainda a circulação de actores. A estrutura principal apresenta a opção de formar um único plano, assegurada por dois eixos (cf. Last, 1962), recriando assim a circularidade do tempo, ao passo que a articulação de espaços dentro desta estrutura desdobra a economia (apud Cooper, 1962), a angularidade e a fragmentação do libreto e da música, de maneira que aquela estrutura-palco constitui uma ponte entre a atmosfera da Grécia Antiga e o espectáculo. Realmente, a circularidade em articulação com a mobilidade fluida da estrutura-palco recriam o movimento cíclico das estações, acompanhando a concepção grega do tempo, tal como a astúcia de inclinar a plataforma em direcção à audiência origina um efeito de apóstrofe, que a convida a participar do ritual que acontece diante dos seus olhos. $\mathrm{O}$ facto de os artistas não poderem desrespeitar a marcação de cena, sob pena de caírem, enfatiza a distância crítica que a audiência deve guardar dos acontecimentos em palco, reconhecendo-se nesta solução o efeito de distanciamento que Tippett pretendia conseguir. A cena grega é também evocada por aquela solução, uma vez que o calçado dos actores contribuía para acentuar a percepção de afastamento e de transcendência.

Efectivamente, a plataforma-palco amplia o espaço de circulação quer no eixo vertical, quer no eixo horizontal. Por um lado, a amplitude vertical salienta a pequenez da estatura humana, denunciando a sua impotência, diferentemente daquilo que as posturas e os trajes sugerem, evocando simultaneamente a percepção de transcendência. Por outro lado, a amplitude horizontal abre um espaço, que se pode compreender como recriação cénica do arbítrio. As diversas formas geométricas inscritas no solo da plataforma-palco autorizam esta leitura, pois mostram 
secções angulares que, assim, recriam a estrutura em mosaico do texto e da música, como quadros independentes, porém relacionados, proximidade que a semântica da cor reforça, complexificando as alusões temporais. Por exemplo, os ocres luminosos aludem à terra, harmonizando-se com os metais da orquestra, reunindo passado e presente, ficção e execução. A cor ocre, sendo uma cor da Natureza, particularmente associada ao Outono, funciona não só como metáfora de perda e de morte, mas também como anúncio de vida, simbolizando o retorno circular. A alusão ao natural continua na cor azul, utilizada para recriar o céu e para o traje de Príamo, ou no branco que Páris criança e Príamo moribundo envergam, aparecendo ambos como vítimas sacrificiais. O negro e o castanho também integram a escala cromática, ocasionalmente invadida por encarnado, expressiva de brutalidade e de crueldade, em geral e, em particular da Guerra de Tróia e da Segunda Grande Guerra.

Relativamente à caracterização, nomeadamente trajes e maquilhagem, os primeiros enunciam tensão entre simplicidade grega e fantasia, como sugere o elmo dourado com chifres de bode, signo de poder e de sacrifício, envergado por Príamo. A segunda, ora lembra uma mistura de burlesco e de kabuki (ver fig. 6), ora se apresenta discreta e elegante, como exemplifica o penteado das personagens femininas, cujas mechas reunidas acima da nuca evocam a tradição grega, também presente nas longas túnicas, discretamente onduladas, tornando as mulheres semelhantes a esculturas (ver fig. 1).

\section{RESGATE DO CORPO DE HEITOR}

Simplicidade, economia e razão dominam esta rescrita (ver fig. 6). Sobre a plataforma desce uma tela triangular em tons ocre e negro, análoga a um tabuleiro de xadrez, que reinventa a angulosidade e a estrutura em mosaico do texto e da música. A alusão ao jogo dentro do jogo (espectáculo) continua a noção de fragmentos interligados, evocando os encruzamentos da vida das personagens, o arbítrio e as suas consequências universais.

A simbologia dos adereços descortina a dimensão ritual desta rescrita: a tela branca sobre o corpo de Heitor associa-o como vítima sacrificial a Páris criança e a Príamo moribundo. O elmo de Aquiles, colocado sobre o solo, ao lado do banco onde este está sentado, indica a suspensão da actividade bélica, de modo que esta cena, do ponto de vista 
FIG. 7

KING PRIAM, DE MICHAEL TIPPETT, ENC. ROBIN LOUGH, 1985,

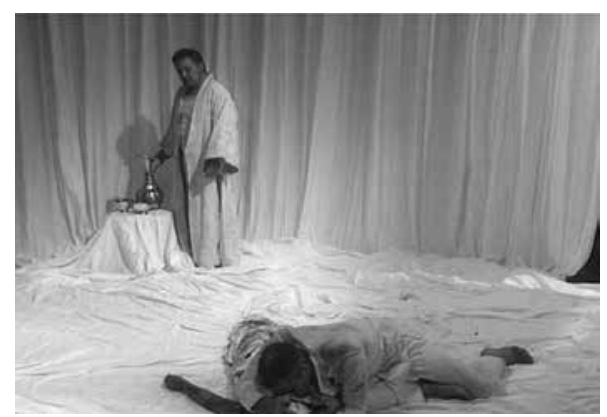

iconográfico, sugere um lugar atemporal, onde se albergam o passado, o presente e o futuro, ou seja, a demanda de glória e honra de Aquiles, a grandiosidade de Príamo e o futuro que os dois homens prevêem. ${ }^{6}$ O deus Hermes transmite uma linguagem corporal indicadora de abertura e de movimento, sugerida pelos joelhos ligeiramente flectidos e o olhar atento, ao passo que o traje e a maquilhagem lembram a Grécia, o burlesco e o kabuki. A plataforma circular e fragmentada alude às trajectórias distintas de Aquiles e de Príamo, indicando o seu cruzamento e a sua convergência, quando o herói compreende que os afectos que se imprimem positiva e profundamente na sensibilidade são inalienáveis do sentido de humanidade.

\section{6.}

Cerca de três décadas depois (1985), é recriada uma reinvenção de King Priam para estúdio, com gravação vídeo. ${ }^{7}$ Esta técnica representa umailusão para a história do espectáculo, porque a câmara introduz um ponto de vista. Todavia, este registo faz parte da história da reinvenção cénica, cumprindo a função decisiva de reforçar a lembrança de que aquilo que a audiência vê é uma demonstração (apud Ballantine, 2008), facilitando ainda o reconhecimento de um «arquivo pretexto» para outras reinvenções.

As técnicas de filme, como, por exemplo, o close-up, orientam a atenção da audiência mais enfaticamente do que a solução da plataforma inclinada, apelando também à sua participação, pois «[s]uch devices [...] enhance the Brechtian aspects of Tippett's opera [...] reminding the viewer that this is a "showing" of something: a demonstration» (idem: 2008).

Aquiles e Príamo conversam acerca da sua morte e sobre os seus futuros assassinos (acto III, cena III).

7 Produção da Kent Opera e registo de imagem em DVD da responsabilidade de Arthaus Music/British Theatre. A realização esteve a cargo de Nicholas Hytner e da Kent Opera. 


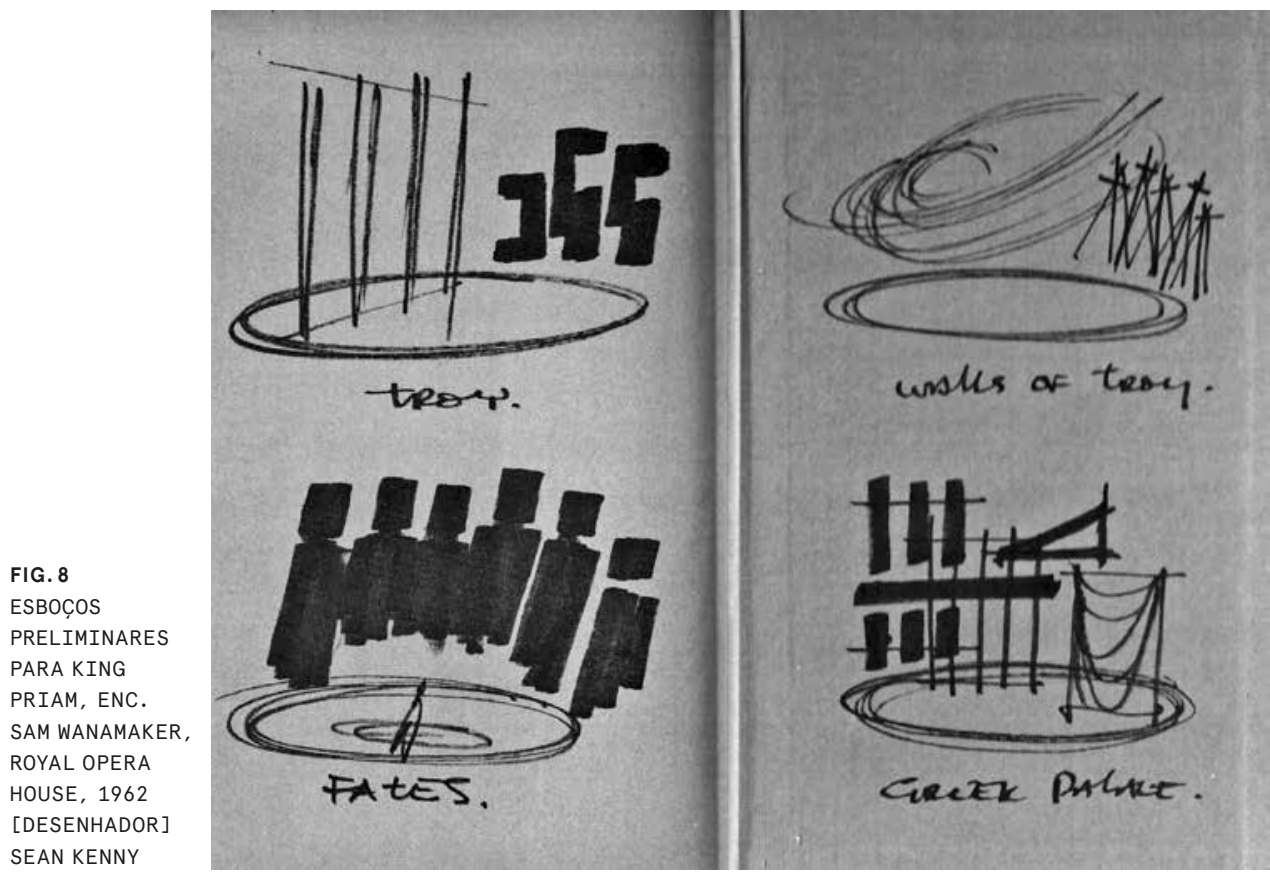

Aquele registo resiste, todavia, à introdução de ilusões que a tecnologia possibilita, tal como também respeita o minimalismo e a estrutura em mosaico de King Priam. Inversamente, a dimensão de espectáculo perde-se, porque o tempo presente é anulado, pois o homem, o seu instrumento mais eficaz, está ausente (apud Barrault, 1950: 98). Pontualmente, os objectos indicam o lugar que a cena procura evocar. Por exemplo, uma cadeira sugere poder e uma porta indica aquilo que é transitório, denotando a fugacidade daquele. A terra sobre o solo alude à Natureza, a cama informa que se trata do quarto de Helena, em Esparta, ao passo que os corredores em ruínas, estreitos, labirínticos e escuros apontam a guerra (ver fig. 2). Os trajes assemelham-se aos uniformes militares da Segunda Grande Guerra, diferentemente das cenas de caça, de brutalidade e de crueldade, em que os artistas vestem unicamente calças. Helena enverga uma longa túnica branca, sendo a única personagem vestida como uma grega durante toda a ópera. As outras personagens femininas envergam trajes semelhantes uma única vez, durante o julgamento de Páris; todavia, aqueles são encarnados, evocando a tensão entre o sexo e a guerra.

A maquilhagem é natural, mas, diferentemente da rescrita de 1962, as personagens usam penteados contemporâneos; mesmo o de Helena seria habitual em 1985, ou até hoje. A concepção do espaço mostra lugares 
completamente destruídos, em alusão à guerra, porém reconhece-se ainda a oposição entre a destruição no exterior e a tranquilidade no interior, formando-se ilhas atemporais que referenciam a alteridade, à semelhança da rescrita de 1962. Pelo contrário, em 1985 não se reconhece imediatamente o mundo antigo, como pretende mostrar a breve análise do ambiente cénico do resgate do corpo de Heitor. A cena acontece na tenda de Aquiles, ao abrigo da guerra. O espaço é composto por lençóis brancos, incluindo uma cama branca, uma mesa baixa, um jarro e dois cálices. O corpo de Heitor jaz no solo, coberto com um lençol branco (ver fig. 7). Aquiles veste um roupão branco, evocando a intimidade e a guerra, pois o tecido de algodão espesso convoca o ambiente de combate, devido à semelhança com os quimonos utilizados nas artes marciais. $\mathrm{O}$ cabelo curto e a barba aparada acompanham o semblante pensativo e sério, diferentemente da aparência descuidada durante o espectáculo ${ }^{8}$, como mostram as fotografias de cena. O corpo de Heitor está sujo de sangue e de terra, tal como as roupas humildes de Príamo. Os seus cabelos grisalhos estão cortados muito curtos, contribuindo para enfatizar a expressão extenuada, que faz sobressair a tristeza que os seus olhos transparecem. Estes elementos cenográficos, aliados à linguagem corporal e à manipulação de objectos, formam um todo alusivo ao tempo.

Em primeiro lugar, a relação entre espaço e tempo, referenciada pela tenda de Aquiles, introduz a dimensão atemporal, supramencionada, que por sua vez está encaixada no tempo cronológico, sugerido pelo exterior da tenda, onde decorre a guerra. A cor branca preenche aquela ilha atemporal, identificando-a como lugar sagrado, ou seja, de proximidade com o transcendente, noção que os objectos salientam, nomeadamente o jarro, utilizado para uma libação e para um brinde, recriando o ritual do sacrifício e da celebração. $\mathrm{O}$ ambiente completamente branco amplia universalmente esta metáfora, sugerindo o sacrifício comum. A intimidade da tenda enuncia ainda o conflito como tensão entre o privado e o público, aludindo à impossibilidade de fronteirar inequivocamente cada um. O corpo de Heitor sobressai, à luz desta compreensão, como solução cenográfica para indicar a interpenetração do íntimo e do público. $\mathrm{O}$ acto de guardar o corpo mostra a transgressão entre aquelas duas dimensões, enfatizada em dois momentos decisivos mediante a gestualidade ritual dos artistas. $O$ primeiro indica a comunhão entre dois homens que bebem juntos; o segundo, por oposição à brutalidade 
da guerra, regista o gesto de civilização que representa Aquiles erguer o corpo de Heitor suavemente, colocando-o nos braços de seu pai, Príamo. O movimento lento e exacto sugere planeamento, legitimando a comparação com um ritual.

$7 \cdot$

A rescrita de 2014 (enc. James Conway) estreou no Linbury Studio Theatre, um espaço pequeno, mas que potencia a estruturação organizada do espaço cénico (ver fig. 3). Semelhante a um bunker (Hugill, 2014), esta área é composta por linhas verticais, muito semelhantes às que mostram os esboços do cenário de 1962 (fig. 8), descortinando-se uma herança, voluntária ou não. A síntese da gramática cénica potencia o seu alcance simbólico e estimula a capacidade inventiva, como demonstram as pequenas astúcias que potencializam a capacidade de metamorfose do espaço. Por exemplo, as velas indicam o lugar comum de prece; o biombo, com alterações subtis, representa a tenda de Aquiles ou o lugar onde Príamo vai reflectir sozinho. Os artistas circulam sobre uma estrutura erguida na parte de trás. Ao centro do palco, um pódio baixo unido a uma estrutura metálica serve de foco para a acção, constituindo ainda um suporte à cena e ao cenário (ver fig. 3), onde os momentos decisivos da história convergem. Por exemplo, o lamento de Andrómaca, que teme pela vida do marido e do filho numa guerra sem sentido, ou a meditação de Aquiles e a emoção de Príamo. Neste local, as personagens descobrem uma resposta individual ao seu sentido de vida.

O guarda-roupa reflecte quase toda a escala cronológica, que enfatiza a noção de universos temporais distintos, assim como alude à fragmentação do homem contemporâneo, aliança que indica uma «transmemória» (Serrão, 2007). Identificam-se elementos pré-históricos, como armas feitas de ossos de animal e peles (apud Ashley, 2014), utilizados em articulação com elementos actuais, incluindo indicadores de ambientes nocturnos de margem, como a maquilhagem acentuada e o couro negro, conferindo especificamente a Hermes a aparência de uma personagem de um clube de sexo (ver fig. 3). Esta percepção subjectiva reforça a díade sexo-guerra, decisiva na ópera, apontando uma dimensão autónoma da encenação, que não foi planeada (Conway, 2015). A maquilhagem, em geral, é semelhante a uma máscara e esconde o rosto dos artistas, evocando simultaneamente a camuflagem de guerra, o excesso e a alteridade e reforçando 
FIG. 9

KING PRIAM, DE MICHAEL

TIPPETT,

ENC. JAMES

CONWAY,

ENGLISH

TOURING

OPERA, 2014,

[F] RICHARD HUBERT SMITH

* CORTESIA DA SCHOTT MUSIC

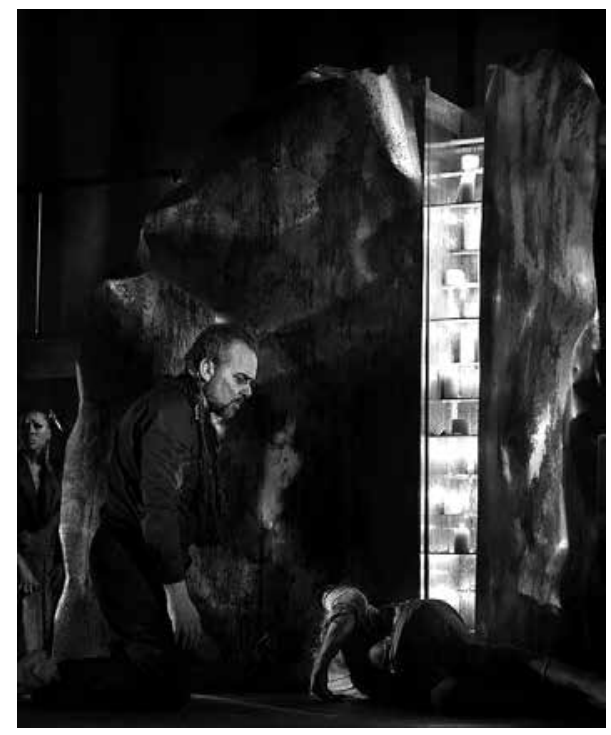

o antagonismo entre aquilo que a personagem é, aquilo que pretende parecer e aquilo que se vê subordinada a ser, numa alusão contínua ao acto performativo como encarnação (Schechner, 2013: 128). Os tecidos encarnados indicam a morte, a vida, a crueldade e a brutalidade, onde se inclui a profanação da vida, compreendida como lugar sagrado manchado por actos violentos. Utiliza-se o negro, os tons ocres e os beges, à semelhança da primeira produção, mas diferentemente da rescrita de 1985, com excepção para o negro.

A concepção do espaço é minimalista, todavia o guarda-roupa é exuberante, inversamente às cenografias de 1962 e de 1985. Esta reinvenção, contudo, transmite depuração, como mostra a cena do resgate do corpo de Heitor (ver fig. 6), onde Príamo está descalço, desornamentado, envergando um par de calças e uma camisa muito simples, cujo desaprumo é acentuado pela postura curvada, expressiva de desalento, inversamente ao garbo inicial. Do mesmo modo, o corpo de Heitor, sujo, é abandonado sem qualquer cobertura. Colocada sobre o pódio, a tenda é referenciada por um pano branco disposto sobre o biombo supramencionado, cuja superfície ondulada evoca a noção temporal que se identificou nas rescritas anteriores, nomeadamente, a fluidez de um movimento que retorna. Neste local, a compaixão desperta como sendo algo universal, por isso é aqui que Heitor é restituído a Príamo. Todavia, nesta rescrita (2014), Príamo não abraça o filho morto; ao invés, contempla-o com uma expressão de profunda dor, quase animalesca, porque sugere impotência racional. 
O espaço cénico contém a noção de centralidade e de universalidade, sendo que a fragmentação e a destruição sobressaem como consequência da acção humana. Por isso, a neutralidade do espaço é indicada pelo vazio e pela iluminação pontual (apud Appia, 1988: 362). Justamente, as personagens contaminam o espaço com movimento, ao passo que soluções simples, unicamente as necessárias e suficientes, evidenciam aquela neutralidade. Este é o caso do lençol branco, que indica a intimidade de Aquiles e simboliza o despertar da sua compaixão; contudo, a solução de o manchar com um líquido encarnado aponta a passagem de Hermes, que o manipula, imprimindo-lhe movimento. Assim, o lençol mostra também o destino de morte, sugerido desde o início pela astúcia de fazer esconder flechas sob as roupas do berço de Páris (apud Ashley, 2014). Adicionalmente, o fogo na tenda de Aquiles, que é sempre um espaço aberto, evoca a indiferença do espaço à presença humana $\mathrm{e} a$ impossibilidade de fabricar um espaço completamente íntimo.

Transparece ainda uma concepção antropológica, devida aos materiais, fetiches, tótemes e maquilhagem indígena, indicando uma atmosfera invadida pelo instinto e matizada pelo ritual. A sumptuosidade do guarda-roupa, aliada àqueles aspectos, por um lado, consolida a noção de que a acção humana modifica o espaço e quase o excede, percepção que sobressai devido à exiguidade das salas (apud Fairman, 2014). Por outro lado, enfatiza a indigência que domina o espaço e as personagens, após as suas perdas íntimas, tornando indistintos os membros da família real e as presenças humildes do ancião vidente, da ama e do guarda, uma tríade sóbria e irrepreensível, quase japonesa (apud Conway, 2015). ${ }^{9}$

A mistura de estilos sugere a pluralidade identitária, ao passo que o coro, que o encenador compara ao coro grego ${ }^{10}$, a máscara, a linguagem sintética e o estrangulamento do espaço não separam de maneira evidente o que é público do que é privado, originando uma tensão entre a fragmentação humana e impressão de unidade. A ausência de um corredor de fuga, a itinerância e o instinto como fonte de brutalidade e de crueldade são aspectos herdados da cenografia de 1962, que a instalam como arquivo pretexto das recriações de 1985 e de 2014, observando-se uma atmosfera de perda e de confusão de elementos em crescendo.

9 Entrevista privada, não publicada, remetida e respondida via correio electrónico.

10 «The chorus was wonderful, and they enjoyed being on stage for almost the whole show, like a Greek chorus» (Conway, 2015). 


\section{8.}

Em conclusão, King Priam possibilita descortinar uma tripla acepção da noção de «arquivo pretexto». Em primeiro lugar, como conjunto de documentos que mostram e registam modos de ver e de dar a ver. Em segundo lugar, como monumento efémero de uma realidade fugaz, que inspira e orienta reinvenções devido à sua universalidade. Em terceiro lugar, a comparação entre esboços, entrevistas aos produtores e fotografias de cena descortinam um plano ideal, o da concepção e um plano concreto, o da realização viva do espectáculo propriamente dito. $\mathrm{O}$ ímpeto para a reinvenção conduz à noção de «obra em movimento», seguindo por duas vias: por um lado, como organismo vivo com mais de cinco décadas e, por outro, como espectáculo itinerante (2014), conferindo não só um sentido literal àquela noção, mas também estimulando as variantes cénicas ditadas pelos diversos espaços, em particular a marcação de palco e o movimento de artistas, eventualmente registadas em fotografias.

As cenografias mencionadas confirmam aquela compreensão. $\mathrm{O}$ espaço circular em 1962 alude directamente à noção grega do tempo. Contudo, em 1985 a solução cénica inclui, por exemplo, o corredor labiríntico em ruína, ao passo que, em 2014, conduz as personagens ao pódio central, primeiro individualmente e depois colectivamente. As diversas soluções veículam a percepção comum de que os pontos de chegada não são o fim, mas sim começos, pretextos e movimento universal perpétuo. A estética da compaixão mediada pelo momento seleccionado, o resgate do corpo de Heitor aponta para a apatia do páthos, ou seja, para uma linguagem cada vez mais minimalista, até à mudez da visão oratória (apud Aristóteles, 2011: 50b16-20), perfazendo uma «dramaturgia do silêncio» (Féral, 2007: 67).

Finalmente, a cenografia viva de Conway afigura-se arquivo pretexto para a realização, no futuro, de um estudo sobre a memória dos corpos performativos em salas de espectáculo diversas, o que possibilitará expandir as noções de «arquivo pretexto» e «obra em movimento», complementando a história genética de King Priam, que esta pesquisa pretendeu iniciar. 


\section{REFERÊNCIAS BIBLIOGRÁFICAS}

APPIA, Adolphe (1988), Oeuvres Complètes, t. III, Lausanne, L’Âge de L’Homme.

Aristóteles (2011), Poética, trad. Ana Maria Valente, pref. Maria Helena da Rocha Pereira, Lisboa, Fundação Calouste Gulbenkian.

ASHLEy, Tim (2014), «"King Priam” Review», http://www.theguardian.com/music/2014/feb/14/king-priam-review, [24 de Fevereiro de 2016].

Ballantine, Christopher (2008), «King Priam: Tippett», www.opera.archive.netcopy.co.uk/article/ june2008/107, [24 de Fevereiro de 2016].

BARRAUlt, Jean-Louis (1950), «The Theatrical Phenomenon», Educational Theatre Journal, 17, pp. 89-100.

CONWAY, James (2015), entrevista privada sobre King Priam, [inédita].

ClARKe, D. (2001), The Music and Thought of Michael Tippett, Cambridge, Cambridge University Press.

COOPER, Martin (1962), «"King Priam” Reveals a Master of Opera [crítica, The Daily Telegraph, 28 de Maio?].

FAIRMAN, Richard (2014), «King Priam, Linbury Studio Theatre, Royal Opera House, London: review», http:// www.ft.com/cms/s/2/16d66190-988o-11e3-8503-00144feab7de.html, [24 de Fevereiro de 2016].

FÉRAL, Josette (2007) «Moving Across Languages», trad. Leslie Wickes, Yale French Studies, 112, pp. 50-68.

-- (s. d.), «Pour une Génétique de la Réprésentation: Prise 2», http://www.processusdecreation.uqam.ca/Page/ Document/genetique_prise2.pdf, [24 de Fevereiro de 2016].

Figueira, Ana Rita Barros (2013), «King Priam» de Michael Tippett: Épica, tragédia e perdão, Lisboa, Universidade de Lisboa [dissertação de mestrado].

G OLDHILL, Simon (2007), How to Stage Greek Tragedy Today?, Chicago, Chicago University Press.

GRÉSILlon, Almuth (1996), «De L'Écriture du Texte de Théâtre à la Mise en Scène», Cahiers de Praxématique, 26, https://praxematique.revues.org/2979, [24 de Fevereiro de 2016].

-- (2005), «La Critique Génétique: Aujourd'hui et demain» http://www.item.ens.fr/index.php?id=14174, [24 de Fevereiro de 2016].

HEBER LE, J. P. (2006), Michael Tippett ou L'Expression de la Dualité et en Mots et Notes, Pâris, L'Harmmatran.

HOWARD, Pamela (2005), What is Scenography, Londres, Routledge.

HUGILL, Robert (2014), «Welcome new production of Tippett's underrated opera» http://www.planethugill. com/2014/02/tippetts-king-priam-from-english.html, [24 de Fevereiro de 2016].

JOHN, Nicholas (ed.) (1985), The Operas of Michael Tippett, Londres, John Calder.

KEMP, I. (ed.) (1965), Michael Tippett: A Symposium of His Sixtieth Birthday, Londres, Faber \& Faber.

LAST, R. (1962), «So Exciting and in a Soup Plate», The Daily Herald, [Londres, 28 de Maio].

MARÍn, Louis (1988), «Le Cadre de la Représentation et quelques-unes de ses figures», Les Cahiers du Musée National d'Art Moderne, Verão, pp. 62-81.

MCCONACHIE, Bruce (2007), «Falsifiable Theories and Performance Studies», Theatre Journal, 59 (4), pp. 553-77.

P. A. (1962), «Michael Tippett's New Opera», Musical Times, Julho.

POlla RD, Rowena e ClARKe, David (1998), «Tippett's King Priam and the Tragic Vision», in ClARKE, D. (ed.), Tippett Studies, Cambridge, Cambridge University Press, pp. 166-85.

PORTE R, A. (1962?), «Coventry Theatre: King Priam: Review», The Financial Times, Londres.

RoBinson, Susan (2002), Michael Tippett: Music and Literature, Londres, Ashgate.

SCHECHner, Richard (2013), «Le "Point de Contact” entre Anthropologie et Performance», Communications, 92, pp. 125-46.

SERRA, José Pedro (2006), Pensar o Trágico, Lisboa, Fundação Calouste Gulbenkian. 
SERRÃo, Vítor Veríssimo (2007), A Trans-Memória das Imagens: Estudos iconológicos de pintura portuguesa (séculos XVI-XVIII), Chamusca, Cosmos.

TIPPETT, Michael (1962), «Reflections on the First Production», pp. 12-13.

WANAMAKER, Sam (1992), «A Conversation with Bruce Duffie», http://www.bruceduffie.com/wanamaker.html, [24 de Fevereiro de 2016].

\section{ANA RITA FIGUEIRA}

Ana Rita Figueira é licenciada em Linguística pela Faculdade de Letras da Universidade de Lisboa e mestre em Estudos Clássicos pela mesma instituição, onde defendeu a dissertação intitulada King Priam de Michael Tippett: Épica, tragédia e perdão. O interesse pela figura de Aquiles e, em particular, pelas suas rescritas artísticas decidiu a subordinação da tese de doutoramento ao título Iconografia de Aquiles: Teatralidade, retórica e comunicação na cerâmica grega dos séculos vı e $v$ a. $C$. 